DOI: $10.17805 /$ zpu.2019.3.2

\title{
О науке в современной России
}

\author{
И. М. ИЛЬИНСКИЙ, В. А. ЛУКОВ
}

МОСКОВСКИЙ ГУМАНИТАРНЫЙ УНИВЕРСИТЕТ

В статье анализируется проект Федерального закона «О научной и научно-технической деятельности в Российской Федерации». Проект призван заменить принятый в 1996 г. Федеральный закон «О науке и государственной научно-технической политике» (от 23 августа 1996 г. №127-Ф3), включив и правовые нормы Федерального закона от 7 апреля 1999 г. №70-ФЗ «О статусе наукограда Российской Федерации».

Достоинства и недостатки законопроекта рассматриваются на фоне процессов в российской науке, выдвигающих среди прочего задачу создания гуманитарного щита в отношении внедрения в жизнь новых научных идей и технологий. Показываются направления такого сопровождения инноваций, которые может создать союз гуманитарных наук.

Ключевые слова: федеральный закон; научная деятельность; научно-техническая деятельность; российская наука; российское законодательство о науке; ученые; научные работники; гуманитарные науки 


\section{BВЕАЕНИЕ}

поры о науке, ее месте в современном российском обществе продолжаются с неутихающей силой - но больше всего в аспекте институциональных, финансовых и кадровых перемен. Аанные Высшей школы экономики (ВШЭ), опубликованные в 2017 г., свидетельствуют о том, что в 2016 г. объем внутренних затрат на исследования и разработки достиг в России 943,8 млрд руб., что составляет 37,3 млрд долл. США, при этом Россия заняла десятое место в рейтинге ведущих стран мира по величине этого показателя 1 . Заметим, что российское достижение этого времени в сравнении с затратами США (502,9 млрд долл.) в 13,5 раза меньше. Но не только в деньгах на науку дело.

Проблема не исчерпывается этим, как и мировыми рейтингами, числом нобелевских лауреатов, обилием научных публикаций и их цитированием. Вполне прав проректор МГИМО по научной работе Е. М. Кожокин, когда отмечает: «От многовекового национального наследства невозможно отказаться без катастрофических последствий. <...> Когда говорят, что наука движется за счет больших денег, это заблуждение. Аеньги нужны, но великие открытия делают прежде всего те, кто не думает о деньгах. О деньгах должны думать другие, кто призван обеспечить ученому условия. Гегель как-то сказал: “Понятие - это застывшая страсть”. В науке страсть важна не менее денег» ${ }^{2}$.

Призывы к повышению эффективности науки находятся в противоречии с тем, что система Российской академии наук практически разрушена, в 2013-2018 гг. Федеральное агентство научных организаций (ФАНО России) как исполнительный орган федеральной власти, которому была подчинена РАН, занималось собственностью институтов академии, бесконечным переназначением их директоров, но для развития науки как интеллектуальной деятельности, формы общественного сознания ничего не было сделано. Отчет президента РАН А. М. Сергеева на общем собрании РАН в 2018 г. излагался в электронных СМИ под заголовками вроде "Академия возвращается», многие вопросы были решены в ходе неоднократных встреч А. М. Сергеева с Президентом РФ В. В. Путиным³ ${ }^{3}$ но пять лет всевластие ФАНО России, при всей критике академиков, продолжалось и ничего не дало науке как таковой. Ожидания научных прорывов потонули в организационных реформах.

Та же история с защитой диссертаций: ужесточение условий защиты, закрытие массы диссертационных советов, нередко по формальным причинам, а точнее - придиркам, требование публикации основных положений диссертации, а вместе с тем безоглядное доверие чиновничества ВАК к «Антиплагиату», который признает неоправданным заимствованием то, что диссертант берет в своих же книгах и статьях; сужение круга оппонентов и ведущих организаций предписанием обязательного наличия у них работ по той же теме, что и у диссертанта (непонятно, откуда тогда может появиться научная новизна, связанная с развитием научных школ, забытых в таком подходе к научным решениям в диссертациях), а в это время мировая наука давно идет по пути междисциплинарности и разрушения барьеров, отделяющих одну науку от другой, более того - одну отрасль науки от другой, - все это и многое другое, конечно, привело к резкому сокращению числа защит, но в показателях вузов, например, высокий уровень «остепененности» не только не уменьшился, но в некоторых случаях еще и увеличился. В 2015 г. в сравнении с 2006 г. число молодых кандидатов наук до 29 лет увеличилось с 4,5 до 5,3\% от общей численности исследователей (Российская молодежь ... , 2017: 67), но әксперты подчеркивают: «Трудно прогнозировать, 
сохранится ли в дальнейшем тенденция к усилению роли молодежи в науке, поскольку динамика численности исследователей тесно связана с динамикой подготовки кадров высшей квалификации, а численность аспирантов уменьшается начиная с 2011 г. В 2013 г. она составляла 90,3\% от уровня 2006 г., в 2014 г. - 82,0\%, а в 2015 г. - 75,2\%... Снижение общей численности аспирантов ожидаемо отразилось на показателях выпуска из аспирантуры: в 2013 г. было выпущено почти 35 тыс. человек, в 2014 г. - чуть больше 28 тыс., в 2015 г. - около 26 тыс. человек, т. е. за два года данный показатель сократился на 25,6\%. Важно заметить, что сокращение произошло в первую очередь за счет молодых аспирантов (до 29 лет включительно)...» (там же: 67-68). При этом важна такая констатация: «Число защищенных кандидатских диссертаций снизилось во всех отраслях науки, но наиболее значительно - в гуманитарных областях: сильнее всего (не менее чем на 70\%) сократилась численность лиц, защитивших кандидатские диссертации по юридическим, экономическим, педагогическим, социологическим и философским наукам» (там же: 68-69).

На этом противоречивом фоне и должна проводиться независимая оценка предлагаемого для принятия в качестве федерального закона законопроекта «О научной и научно-технической деятельности в Российской Федерации».

\section{О ПРОЕКТЕ ФЕАЕРААЬНОГО ЗАКОНА «О НАУЧНОЙ И НАУЧНО-ТЕХНИЧЕСКОЙ АЕЯТЕАЬНОСТИ В РОССИЙСКОЙ ФЕАЕРАЦИИ "}

Проект Федерального закона «О научной и научно-технической деятельности в Российской Федерации» призван заменить принятый в 1996 г., т. е. почти четверть века назад, Федеральный закон от 23 августа 1996 г. № 127-Ф3 «О науке и государственной научно-технической политике», включив и правовые нормы Федерального закона от 7 апреля 1999 г. № 70-Ф3 «О статусе наукограда Российской Федерации», которому тоже много лет: со времени принятия прошло уже 20 лет. Первый из этих законов многократно подвергался изменениям и дополнениям: 34 раза он принимался в обновленной редакции (от 19.07.1998 №111-Ф3, от 17.12.1998 № 189-Ф3, от 03.01.2000 № 41-Ф3, от 29.12.2000 № 168-Ф3, от 22.08.2004 № 122-Ф3, от 30.06.2005 №76-Ф3, от 31.12.2005 №199-Ф3, от 04.12.2006 № 202-Ф3, от 01.12.2007 №308-Ф3, от 23.07.2008 № 160-Ф3, от 30.12.2008 № 309-Ф3, от 10.02.2009 № 18-Ф3, от 02.08.2009 № 217-Ф3, от 27.12.2009 №358-Ф3, от 08.05.2010 № 83-Ф3, от 27.07.2010 № 198-Ф3, от 01.03.2011 № 22-Ф3, от 19.07.2011 № 248-Ф3, от 20.07.2011 № 249-Ф3, от 21.07.2011 № 254-Ф3, от 06.11.2011 № 291-Ф3, от 03.12.2011 №385-Ф3, от 28.07.2012 №135-Ф3, от 03.12.2012 № 240-Ф3, от 07.05.2013 № 93-Ф3, от 02.07.2013 № 185-Ф3, от 27.09.2013 № 253-Ф3, от 02.11.2013 № 291-Ф3, от 22.12.2014 № 443-Ф3, от 20.04.2015 № 100-Ф3, от 13.07.2015 № 270-Ф3, от 23.05.2016 № 148-Ф3, от 23.05.2016 № 149-Ф3, от 26.07.2019 №232-Ф3) и четыре раза в него вносились изменения другими федеральными законами (от 27.12.2000 № 150-Ф3, от 30.12.2001 № 194-Ф3, от 24.12.2002 № 176-Ф3, от 23.12.2003 № 186-Ф3). Во второй из названных законов изменения и дополнения вносились четыре раза (22 августа 2004 г., 18 октября 2007 г., 27 декабря 2009 г., 2 июля 2013 г.), причем были исключены статьи 5, 6, 7, утратившие регулирующую силу с 2017 г.

В научном и научно-технологическом обеспечении общественного развития России принятие целого ряда нормативных правовых актов на уровне федерального законодательства (Федеральный закон от 29 декабря 2012 г. № 273-Ф3 «Об образовании в Российской Федерации» (ред. от 26.07.2019)) и федеральных органов исполнительной власти, утвержденных Правительством РФ концепций («цифровой экономики» 
и др.) в указанной сфере, а также частые переработки Федерального закона «О науке и государственной научно-технической политике» и стремление к укрупнению законодательства о науке и государственной научно-технической политике, разработка проекта нового федерального закона, представленного на обсуждение, являются актуальными и своевременными.

Структура законопроекта не совпадает со структурой принятого в 1996 г. федерального закона, но она вполне логична и в основе может быть сохранена, хотя структура закона 1996 г. была продуманной применительно к выдвижению на передний план регулирования науки и лишь в качестве ее продолжения - соответствующей деятельности. Но надо учитывать, что, во-первых, в федеральном законе 1996 г. наука как таковая появилась только в названии закона, сам же он регулировал научную (научно-исследовательскую) деятельность; во-вторых, принятый закон неправомерно устанавливал основы государственной научной политики, поскольку часть 3 статьи 80 Конституции Российской Федерации отнесла к числу прерогатив Президента Российской Федерации «в соответствии с Конституцией Российской Федерации и федеральными законами определять основные направления внутренней и внешней политики государства ${ }^{4}$. Статья 3 законопроекта в этой части также нуждается в корректировке.

В новом законопроекте появились правовые новеллы. В частности, статья 4 определяет правила подготовки и представления Государственного доклада о реализации научно-технической политики в Российской Федерации и о важнейших научных достижениях. То, что функции по подготовке и представлению доклада возлагаются на Российскую академию наук, а не на какой-либо орган исполнительной власти, означает некоторую независимость авторского коллектива доклада от государственных органов, включая возможность при необходимости вести критику тех или иных позиций органов государственной власти с учетом мнения структур гражданского общества. Это было бы важно для развития научной и научно-технической деятельности в стране.

Существенно появление в законопроекте норм, определяющих правовой статус ученого. Статья 29 законопроекта, посвященная этому, пока требует доработки, чтобы была яснее разница ученого и научного работника, статус которого представлен в статьях 30, 31, 32. Но в своей основе заслуживает поддержки выделение ученого как одного из основных субъектов научной и научно-технической деятельности. Это важно и в связи с тем, что пока в роли такого субъекта выступают повсеместно научные работники, номенклатура и требования к научной аттестации которых устанавливаются Правительством РФ. Ученый в правовом аспекте пока не имеет регламентации прав и обязанностей, кроме как в означенном законопроекте, между тем развитие науки обеспечивается именно этой категорией граждан.

\section{НЕАОСТАТКИ ЗАКОНОПРОЕКТА}

Наиболее существенным недостатком законопроекта представляется то, что в нем научная и научно-техническая деятельность в очень малой мере предполагает, что значительная и перспективная часть этой деятельности проходит в организациях высшего образования или в связи с ними. Хотя в тексте не раз встречаются нормы, относящиеся к этим организациям, но они находятся как бы на периферии правового регулирования, частью исходя из того, что есть законодательство об образовании, которое не требует дублирования. Однако дело здесь в установке авторов законопро- 
екта: как в Федеральном законе «Об образовании в Российской Федерации» наука представлена формально, без понимания того, что ее развитие зависит от деятельности вузов, от включения в науку новых поколений, так и в данном законопроекте наука связывается с развитием инфраструктуры, с требованиями к соискателям научных степеней и научных званий, а не с перспективами подготовки к научной деятельности в вузах. Особенности разделения права на отрасли, специфика законотворческого процесса многое сделать не позволяют, но установка авторов законопроекта важна при отборе предметов регулирования.

В отдельных статьях этот недостаток законопроекта проявляется, как и другие, на которые обратим внимание.

Статья 2 посвящена толкованию применяемых в законопроекте понятий. Но состав этих понятий не соотнесен с их применением в тексте. Так, понятие «научноэкспертная деятельность» далее в законопроекте не используется. Полный повтор с частью 7 статьи 2 содержит часть 3 статьи 11, с частью 8 статьи 2 - часть 5 статьи 11 (первое предложение). Часть 6 статьи 2 («докторантура - форма подготовки научных кадров») совпадает с частью 1 статьи 35, при этом часть 2 статьи 35 ничего не прибавляет к постановлению Правительства РФ от 4 апреля 2014 г. № 267 «Об утверждении Положения о докторантуре», являясь отсылочной нормой. В перечне основных выделяется понятие «субъект научной, научно-технической деятельности» (ч. 5 ст. 2), но оно используется в законопроекте только шесть раз (ч. 1 и 2 ст. 1, ч. 4 ст. 2, ч. 2, ст. 12, ст. 24, ч. 1 ст. 46), причем оно или заново толкуется, или без него можно обойтись.

Статья 3 закрепляет основные принципы, из которых исходит соответствующая деятельность государства и ее правовое обеспечение, но содержание этих принципов не выстроено. Например, часть 4 - «создание благоприятных условий для реализации научной и (или) научно-технической деятельности» - совпадает с частями $1,2,9$ по смыслу.

В статье 8 полномочия субъектов Российской Федерации касаются в основном регулирования в вопросах присвоения ученых степеней и званий (передано от Российской Федерации только одно полномочие «по подтверждению документов об ученых степенях и ученых званиях», оно наиболее подробно представлено в статье 8, другие - между делом; больше полномочий в статье 9 у органов местного самоуправления). Часть 6 статьи 8 определяет задачи по отношению к «федеральному органу исполнительной власти, осуществляющему функции по контролю и надзору в сфере образования и науки», что повторяет одно из изменений в редакции от 26 июля 2019 г. Федерального закона «О науке и государственной научно-технической политике». Но в законодательстве об образовании (Федеральный закон «Об образовании в Российской Федерации») указан федеральный орган исполнительной власти, осуществляющий функции по контролю и надзору в сфере образования (статья 93 названного закона). Правильнее было бы уточнить, что в данном случае имеется в виду орган в сфере высшего образования и науки (исходя из Указа Президента РФ от 15 мая 2018 г. № 215 «О структуре федеральных органов исполнительной власти»).

Статья 9: представленная в части 3 верная установка на независимость финансов местного самоуправления от государственных органов (ст. 132 Конституции РФ) не соответствует реалиям по финансированию науки из средств местного бюджета. Надо бы добавить здесь: при соответствующей поддержке федеральных органов, органов субъектов Российской Федерации. Иначе невозможно осуществить пункт 5 (стро- 
ительство и содержание жилищного фонда) и другие полномочия местного самоуправления в сфере науки и научно-технической деятельности, тем более что в тексте ниже такая финансовая поддержка предусмотрена применительно к наукоградам и другим формам науки на территории местного самоуправления.

Статья 10: представленная в части 4 система научной и (или) научно-технической деятельности обозначает только государственные механизмы регулирования (кроме пункта 2 части 4, который можно понимать и расширительно: «научные организации, ученых и научных работников, их объединения»). Совсем в системе нет вузов. Нет общего целеполагания в сфере науки (кто и в какой форме это осуществляет). Обозначены «государственные академии наук» (пункт 4 части 4), но нет общественных академий и других структур гражданского общества (объединения ученых покрывают этот сегмент лишь частично). Нет научных изданий (и соответствующих издающих организаций), выставок, структур повышения квалификации, научных олимпиад и других способов привлечения молодежи в науку. Если задача состоит в представлении системы, то она реализована в основном в том, что относится к государственному обеспечению этой деятельности.

В части 1 статьи 14 в связи с определением целей интеграции научной и образовательной деятельности указывается и «привлечение обучающихся к проведению научных исследований под руководством научных работников». Исходя из статьи 50 Федерального закона «Об образовании в Российской Федерации» надо бы учесть и научных работников образовательных организаций, лучше использовать правовой термин этой статьи - научно-педагогические работники. В качестве руководителей могли бы быть названы и ученые, которые не привязаны в тексте законопроекта к подготовке новых поколений, занятых научной и научно-технической деятельностью. В пункте 2 части 3 статьи 14 определены форма создания лаборатории в образовательной организации и форма кафедры в научной организации в качестве возможных для обеспечения интеграции науки и образования. И это все? А если в образовательной организации вместе с научной организацией создается центр, то это уже не форма интеграции? Авторы законопроекта взяли названные формы из частей 4 и 5 статьи 72 Федерального закона «Об образовании в Российской Федерации», но и там использованы ограничения по термину, а не по существу. Аучше использовать термин «структурное подразделение» (что сделано в данном законопроекте в части 4 статьи 20; есть и перечни структурных подразделений в части 2 статьи 21). Не учтено, что федеральные государственные стандарты высшего образования по основным направлениям подготовки предусматривают в вузах в качестве обязательной научноисследовательскую практику обучающихся. Между тем это еще одна из форм интеграции научной и образовательной деятельности.

В статье 15 возникает противоречие между частями 1 и 9 в отношении РАН: из части 1 не следует, что РАН - государственная академия наук, что, конечно, не так.

Статья 19: при установлении функционала фондов поддержки научной и научнотехнической деятельности нет указаний на ограничение такой поддержки по основаниям отнесения организации, предоставляющей условия для реализации проекта, к числу бюджетных организаций или организаций иной формы собственности с государственным участием или требование к руководителю проекта иметь не менее пяти публикаций в журналах, представленных в международных (частных) базах Scopus или Web of Science. Между тем такие требования выдвигаются. В интересах развития российской науки и соблюдения объявленного в законопроекте принципа свободы 
научного и технического творчества было бы важно указать, что никакие ограничения на поддержку научных проектов, кроме их конкурсной экспертизы, устанавливаться не должны.

В части 2 статьи 21 записано, что научная организация может иметь в своей структуре различные структурные подразделения, обеспечивающие осуществление научной деятельности, и далее идет закрытое перечисление структурных подразделений. В нем нет, например, кафедр вузов, предусмотренных пунктом 2 части 3 статьи 14. Закрытый перечень противоречит части 1 данной статьи, устанавливающей, что научные организации самостоятельны в формировании своей структуры.

Статья 41: в статье предусматривается, что действуют федеральные государственные информационные системы, между тем представлена только одна из этих систем, связанная с государственной научной аттестацией. Часть 3 этой статьи противоречит части 5 статьи 42. В целом же название главы 6 законопроекта «Информационное обеспечение научной и научно-технической деятельности» не отражает ее предмета: в статьях 41 и 42 даны нормы, относящиеся только к Федеральной информационной системе государственной научной аттестации, но некорректно относить это ко всему объему информационного обеспечения данной сферы деятельности.

Отмечая недостатки законопроекта, все же заметим, что высказанные замечания не требуют его переработки. В дополнение могла бы быть введена статья о включении студентов всех уровней подготовки (бакалавров, магистрантов, аспирантов) в научную и научно-техническую деятельность.

\section{ЗАКАЮЧЕНИЕ}

Три ключевые позиции - цифровизация, экология человека, человеческий капитал - непосредственно связаны с задачами, поставленными в сфере экономики («цифровая экономика») государством перед российским обществом. Их решение в аспекте гуманитарных исследований, представленное правительству, администрациям регионов, министерствам и ведомствам, позволит своевременно смягчить издержки масштабных и быстрых перемен. Общественные ожидания лучшей жизни в новых условиях, привносимых развитием естественных наук и технологий, не могут быть обмануты, и здесь велика роль гуманитарного щита от перегибов в политике инноваций, всей системы воспитательной работы (Ильинский, 2018; Ауков, 2017).

Более всего имеют значение исследования новых поколений, которые в конечном счете определят жизнестойкость нововведений, рассчитанных на десятилетия вперед. Аети и молодежь, политика в отношении детства и молодежная политика, воспитание и понимание как основа образования в меняющемся мире, отечественное и всемирное культурное наследие и культура XXI в. должны стать основой планирования НИР в гуманитарной сфере, неотрывной от повседневной жизни и забот сегодняшнего человека - не постчеловека, не киборга, - для которого и существует наука.

\section{ПРИМЕЧАНИЯ}

1 Ратай Т. В. (2017) Затраты на науку в России и ведущих странах мира [Электронный ресурс]// Наука. Технологии. Инновации. 7 сентября. URL: https://issek.hse.ru/data/2017/09/29/ 1158729416/NTI_N_64_0709_2017..pdf (дата обращения: 30.08.2019).

2 Евгений Кожокин: России нужен культ науки, а не культ потребления (2011) [Электронный pecypc] // Агентство новостей Подмосковья. 13 октября. URL: http://www.mosoblpress.ru/44/ 44739/ (дата обращения: 30.08.2019). 
3 Механик А. Академия возвращается [Электронный ресурс] // Стимул. Журнал об инновациях в России. URL: https://stimul.online/articles/science-and-technology/akademiya-vozvrashchaetsya/ (дата обращения: 30.08.2019).

${ }^{4}$ Глава 4. Президент Российской Федерации [Электронный ресурс]// Конституция Российской Федерации. URL: http://www.constitution.ru/10003000/10003000-6.htm (дата обращения: 30.08.2019).

\section{СПИСОК АИТЕРАТУРЫ}

Ильинский, И. М. (2018) Проблема воспитания в условиях глобальных угроз и рисков // Знание. Понимание. Умение. № 3. С. 5-16. DOI: 10.17805/zpu.2018.3.1

Ауков, В. А. (2017) Воспитание в XXI веке и его научное обеспечение в свете тезаурусной методологии // Высшее образование для XXI века: проблемы воспитания: XIV Международ. науч. конференция, МосГУ, 14-16 декабря 2017 г. : доклады и материалы : в 2 ч. / под общ. ред. И. М. Ильинского ; науч. ред. Ч. К. Аамажаа. М. : Изд-во Моск. гуманит. ун-та. Ч. 1. 597 с. С. 502-508.

Российская молодежь: образование и наука (2017) / Н. В. Бондаренко, Ю. А. Войнилов, Г. С. Волкова и др.; Нац. исслед. ун-т «Высшая школа экономики». М. : НИУ ВШЭ. 72 с.

Аата поступления: 30.08.2019 2.

\section{ON THE SCIENCE IN MODERN RUSSIA \\ I. M. ILINSKIY, V. A. LUKOV \\ MOSCOW UNIVERSITY FOR THE HUMANITIES}

The paper analyses the Federal bill "On Scientific and Technological Activity in the Russian Federation". The bill is meant to replace the 1996 Federal law "On Science and State Technological Policy" (23 August 1996, No. 127-FZ), and include the legal norms of the Federal law on 7 April 1999 No. 70-FZ "On the Status of Science City of the Russian Federation".

The advantages and disadvantages of the bill are considered by the authors against the background of the processes in Russian science proposing, among others, the task of creating a humanitarian shield against the adoption of new scientific ideas and technologies. They also demonstrate the course of such an accompaniment to innovations that can be created by a union of the humanities.

Keywords: federal law; scientific activity; scientific and technological activity; Russian science; Russian science law; scientists; academicians; humanities

\section{REFERENCES}

Il'inskii, I. M. (2018) Problema vospitaniia v usloviiakh global'nykh ugroz i riskov. Znanie. Ponimanie. Umenie, no. 3, pp. 5-16. DOI: 10.17805/zpu.2018.3.1 (In Russ.).

Lukov, V. A. (2017) Vospitanie v XXI veke i ego nauchnoe obespechenie v svete tezaurusnoi metodologii. In: Vysshee obrazovanie dlia XXI veka: problemy vospitaniia: XIV Mezhdunarod. nauch. konferentsiia, MosGU, 14-16 dekabria 2017 g. : doklady i materialy : in 2 vol. / ed. by I. M. Il'inskogo ; nauch. red. Ch. K. Lamazhaa. Moscow, Izd-vo Mosk. gumanit. un-ta. Vol. 1. 597 p. Pp. 502-508. (In Russ.).

Rossiiskaia molodezh': obrazovanie $i$ nauka (2017) / N. V. Bondarenko, Iu. L. Voinilov, G. S. Volkova et al. Moscow, NIU VShE. 72 p. (In Russ.).

Submission date: 30.08 .2019$.

Ильинский Игорь Михайлович - доктор философских наук, профессор, ректор Московского гуманитарного университета. Адрес: 111395, Россия, г. Москва, ул. Юности, А. 5. Тел.: +7 (499) 374-78-78. Эл. аapec: iilinskiy@mosgu.ru 
Ауков Валерий Андреевич - доктор философских наук, профессор, директор Центра социального проектирования и тезаурусных концепций Института фундаментальных и прикладных исследований Московского гуманитарного университета, заслуженный деятель науки Российской Федерации. Алрес: 111395, Россия, г. Москва, ул. Юности, д. 5. Тел.: +7 (499) 374-75-95. Эл. aApec: v-lukov@list.ru

Ilinskiy Igor Mikhailovich, Doctor of Philosophy, Professor, Rector, Moscow University for the Humanities. Postal address: 5, Yunosti St., Moscow, Russian Federation, 111395. Tel.: +7 (499) 374-78-78. E-mail: iilinskiy@mosgu.ru

Lukov Valeriy Andreyevich, Doctor of Philosophy, Professor, Director, Centre for Social Planning and Thesaurus Conceptions, Institute of Fundamental and Applied Studies, Moscow University for the Humanities; Honoured Scientist of the Russian Federation. Postal address: 5, Yunosti St., Moscow, Russian Federation, 111395. Tel.: +7 (499) 374-75-95. E-mail: v-lukov@list.ru 